\title{
QUARENTA ANOS DE UMA ELEGIA: Francisco de Oliveira e o Nordeste
}

\author{
Flávio Mendes*
}

\begin{abstract}
Em 2017 completaram-se quarenta anos da publicação de Elegia para uma re(li)gião, de Francisco de Oliveira. Dedicado a analisar a trajetória da Superintendência de Desenvolvimento do Nordeste (SUDENE), da qual o sociólogo fez parte entre 1959 e 1964, o texto se tornou uma referência para o debate sobre a questão regional no Brasil. Além da crítica ao modelo de desenvolvimento que guiou a atuação da SUDENE, sobretudo durante a ditadura, Elegia expõe os impactos do "milagre econômico" sobre o Nordeste e as mudanças na divisão regional do trabalho do país. O texto exprime, também, a visão de uma parte dos intelectuais de esquerda sobre aquela conjuntura social e econômica. A partir da análise dos principais argumentos utilizados pelo autor e do debate sobre o clima que envolveu a elaboração do ensaio, este artigo tem o objetivo de relembrar seu impacto sobre as ciências sociais brasileiras dos anos 1970 e, por fim, refletir brevemente sobre sua atualidade.
\end{abstract}

Palavras-chave: SUDENE. Oliveira, Francisco de. Nordeste. Desenvolvimentismo. Ditadura.

\section{INTRODUÇÃO - DA SUDENE AO CEBRAP}

Durante a segunda metade dos anos 1960, certas convicções que muitos intelectuais da esquerda brasileira tinham a respeito do significado da ditadura desapareceram. Logo após o golpe, era comum a opinião de que seus promotores nadavam contra a corrente da história ao tentarem conter a luta de classes, acirrada no pré-1964, e ao apresentarem um programa econômico antinacional, contrário aos pressupostos nacional-desenvolvimentistas que guiaram a ação dos governos das décadas anteriores. Esse diagnóstico inspirava a esperança de que o Estado autoritário não resistiria muito tempo, condenado por uma agenda equivocada e pela crescente pressão popular. O tempo mostrou, aos poucos, que essas apostas, também compartilhadas inicialmente pelo sociólogo Francisco de Oliveira, estavam equi-

* Universidade Estadual de Campinas (Unicamp). Instituto de Filosofia e Ciências Humanas (IFCH). Departamento de Sociologia.

Rua Cora Coralina, 100 - Cidade Universitária - Campinas/SP. flavio85@gmail.com vocadas. ${ }^{1}$ Para muitos, a ficha caiu entre o final de 1968, com o decreto do AI-5, e o início de 1969, com os primeiros sinais de retomada do crescimento. Esses eventos tiveram grande impacto sobre as ciências sociais brasileiras, cuja produção se voltou, em grande medida, a tentar compreender o sentido mais profundo das mudanças promovidas pela ditadura e pelo "milagre econômico". O regime autoritário, até então considerado frágil e transitório, revelava sua força e dava sinais de que não cairia da noite para o dia. Era necessário, portanto, decifrar o monstro para, assim, combatê-lo.

Uma parte importante da produção intelectual crítica à ditadura surgiu no Centro Brasileiro de Análise e Planejamento (CEBRAP), fundado sob a liderança de Fernando Henrique Cardoso, em São Paulo, no final da década de 1960. Concebido como um abrigo para pesquisadores perseguidos pelo regime autoritário, o Centro concentrou parte de seus esforços na

${ }^{1}$ Oliveira recordou, numa entrevista, sua impressão sobre 1964: "Mas voltando ao golpe: a esquerda brasileira não entendeu direito o golpe. A gente pensava que era um golpezinho de militar latino-americano, não se pensava que fosse durar tanto e que fosse tão profundo, não se tinha ideia realmente. A gente achava que era coisa de seis meses" (Montero; Moura, 2009, p. 160). 
interpretação do modelo de desenvolvimento social e econômico brasileiro, tema que já chamava a atenção de membros da chamada Escola Paulista de Sociologia, pelo menos desde a criação do Centro de Sociologia Industrial e do Trabalho (CESIT), em 1961. ${ }^{2}$ O grupo inicial do CEBRAP era composto por apenas sete "pesquisadores seniores", todos ligados à USP: "Juarez Brandão Lopes, Fernando Henrique Cardoso, Paul Singer, Elza Berquó, Cândido Procópio Ferreira Camargo, José Arthur Giannotti e Octavio Ianni, esse último a partir de 1970" (Sorj, 2001, p. 34). Logo após sua chegada, Ianni convidou Francisco de Oliveira para participar de um projeto de pesquisa ligado ao tema do planejamento, dentro do qual o sociólogo pernambucano ficaria responsável por pensar a questão regional. Esse trabalho não avançou, mas foi vinculado ao CEBRAP que Oliveira pôde realizar suas primeiras grandes pesquisas sobre a economia brasileira.

A trajetória de Oliveira não tinha, até então, grande semelhança com a de seus novos colegas. Formado em Ciências Sociais pela Universidade do Recife, ${ }^{3}$ sua cidade natal, nos anos 1950, ele se dedicou desde cedo ao trabalho em órgãos públicos, como o Banco do Nordeste, sempre na área de economia. Em 1959, ele chegou à recém-criada Superintendência do Desenvolvimento do Nordeste (SUDENE), స్ onde logo se tornaria o substituto imediato do 凶̃ diretor, o economista Celso Furtado. Oliveira atuou na Superintendência até o golpe de

^ ${ }^{2} \mathrm{O}$ CESIT surgiu vinculado à Cátedra I de Sociologia da USP, sob a liderança de Florestan Fernandes, com a parti-

ธิ cipação de Fernando Henrique Cardoso, Octavio Ianni e T. 2006)

${ }^{3}$ Criada em 1946, ela daria origem à atual Universidade

4 "Li então com muito gosto dois livros interessantes: o primeiro, o famoso artigo de Fernando Henrique Cardoso que é a introdução à tese dele sobre o Capitalismo e Escravidão no Brasil Meridional. Tinha uma 'Introdução Metodológi- e pela Guatemala antes de se fixar no México, onde atuou vinculado ao Centro de Estudos Monetários Latino-Americanos, como pesquisador e professor, durante dois anos. Lá ele se tornou amigo de Gabriel Bolaffi, ex-colega de Roberto Schwarz e Michel Löwy no curso de ciências sociais da USP.

De volta ao Brasil no final da década de 1960, Oliveira ainda trabalhou em algumas empresas privadas antes de receber o convite de Ianni para fazer parte do quadro de pesquisadores do CEBRAP. Sua entrada para esse Centro foi decisiva para que a carreira acadêmica se tornasse viável e, também, para que o sociólogo, formado no coração do nacional-desenvolvimentismo, entrasse em contato com o marxismo acadêmico cultivado pela Escola Paulista. ${ }^{5}$ Esse ambiente inspirou o primeiro grande ensaio que ele publicou - Crítica à razão dualista, de 1972 - no qual ataca o dualismo presente nas teses de economistas ligados à Comissão Econômica para a América Latina (CEPAL), entre os quais se destacava Celso Furtado, a partir do uso de conceitos da tradição marxista. Além da referência às noções de imperialismo, mais-valia e luta de classes, entre outras, o marxismo está presente no combate à lógica formal dentro da qual os cepalinos enxergavam as contradições da economia brasileira, muitas vezes reduzida à simples oposição entre atrasado e moderno. Oliveira recorre à lógica dialética e define os polos supostamente antagônicos como complementares.

O trabalho, que se tornou um clássico das ciências sociais brasileiras, não encerrou o interesse de seu autor em rever a experiência do nacional-desenvolvimentismo, que ele vivera intensamente. Durante o exílio, Oliveira teve a ideia de escrever um trabalho sobre

ca sobre a dialética nas Ciências Sociais', na Revista Brasileira de Ciências Sociais editada por Júlio de Oliveira, da Universidade Federal de Minas Gerais. Tomei contato com esse artigo e o livro de um polonês, que era Estanislau Soviski [Stanislaw Ossowski], Estrutura de Classe na Consciência Social" (Mantega; Rego, 1999, p. 101).

5 Boa parte dos pesquisadores do CEBRAP passou pelo famoso Seminário Marx, organizado na Faculdade de Filosofia da USP na década de 1950. Sobre sua história, ver Rodrigues (2011). 
a questão regional, com foco sobre a história econômica e social do Nordeste brasileiro, que tivesse como ponto alto uma análise crítica da trajetória da SUDENE. Ele chegou a elaborar um projeto de mestrado que pretendia apresentar a Florestan Fernandes em São Paulo, no final dos anos 1960, mas o texto se perdeu, e a pesquisa acabou sendo adiada. Esse acidente em seu percurso acadêmico seria visto mais tarde como favorável: "[...] foi melhor, vendo em retrospectiva. Eu ia fazer uma coisa muito furtadiana. Eu não tinha ainda o afastamento suficiente" (Ridenti; Mendes, 2012, p. 602). ${ }^{6} \mathrm{~A}$ boa recepção de Crítica à razão dualista - sobretudo nos debates realizados pelo CEBRAP, dos quais participavam pesquisadores de grande prestígio - sem dúvida transmitiu a segurança necessária para que ele retomasse aquele projeto. Dele resultou o livro Elegia para uma re(li)gião: SUDENE, Nordeste, planejamento e conflito de classes, de 1977.

\section{De volta ao Nordeste}

Elegia é, sem dúvida, o trabalho mais importante de Francisco de Oliveira sobre a questão regional. Elaborado a partir de uma exposição da história social, política e econômica do Nordeste, o texto é ainda atravessado por debates teóricos e conceituais que atestam seu caráter "científico". Mas ele não se limita a esse aspecto: desde as primeiras páginas, percebe-se que certos sentimentos do autor pesaram bastante sobre a escrita. A obra é dedicada à memória de Orieta, a primeira esposa de Oliveira, então recém-falecida; aos trabalhadores, operários e camponeses do Nordeste; a Miguel Arraes e Francisco Julião, quadros políticos da esquerda pernambucana e amigos do autor; e a Mário Magalhães da Silveira, médico sanitarista que atuou ao lado de Oliveira na SUDENE. Essas dedicatórias introduzem uma nostalgia que atravessa todo o texto. Afinal, mais do que

${ }^{6}$ Oliveira atribui a responsabilidade pelo extravio do projeto ao amigo Gabriel Bolaffi. um exercício de reflexão sobre a história do Nordeste, ele ganha a forma de uma revisão da trajetória do próprio autor, obrigado a revisitar momentos em que estavam bem vivas suas esperanças num projeto de região e de país que não vingou. A ruptura com o passado cepalino, confirmada em Crítica à razão dualista, não apagou, portanto, a lembrança da paixão que envolvia seu trabalho na SUDENE. A permanência desse sentimento produz uma tensão entre a tristeza que aquela derrota produziu e a necessidade de um diagnóstico realista sobre as causas do fracasso. Tal conflito se converte numa melancolia, antecipada pelo título do livro: "elegia" é uma canção ou uma poesia de lamento, que neste caso é dedicada a uma região que se converte, através da sílaba adicionada em destaque, numa religião.

Entre Crítica à razão dualista e Elegia para uma re(li)gião é possível traçar muitos paralelos. Ambos os trabalhos abordam um mesmo tema, o processo de expansão do capitalismo no Brasil, e o fazem sem apontar uma grande ruptura entre o modelo econômico anterior e o posterior ao golpe de 1964. O que muda, entre os textos, é o foco. No primeiro, Francisco de Oliveira apresenta uma visão mais geral desse movimento, tendo o país inteiro como objeto. No segundo, a análise se concentra no modo como essa transição afetou o Nordeste. O exercício é ousado, pois o olhar sobre o regional pressupõe um bom conhecimento sobre o nacional e o internacional. De fato, ele toma a periferia como um ponto de partida para tentar compreender e descrever aspectos do todo. ${ }^{7}$ Apesar das semelhanças, há entre as duas obras uma diferença fundamental. Em Crítica à razão dualista, a proximidade do autor em relação à ideologia desenvolvimentista permanece oculta. Um leitor que desconheça sua tra-

${ }^{7}$ Esse método é recorrente em seus trabalhos. Em Crítica à razão dualista, a descrição da economia periférica brasileira serve como instrumento para pensar o sistema capitalista como um todo. Notar a recorrência com que este recurso é utilizado pelo autor ajuda a revelar os motivos da crise que afeta sua produção posterior, sobretudo, a partir da década de 1980, quando conceitos-chave de seu pensamento, como "região" e "nação", perderam espaço entre as ciências sociais. 
jetória, em especial sua participação na SUDE$\mathrm{NE}$ ao lado de Celso Furtado, pode concluir a leitura sem desconfiar da existência desse passado. O mesmo não ocorre em Elegia para uma re(li)gião, que começa pela lembrança daquela relação. Essa diferença, que pode parecer à primeira vista sutil, tem enormes consequências sobre o texto. Elas serão discutidas adiante. Antes, é válido imaginar os motivos que levaram Oliveira a trazer ao primeiro plano esse elemento antes oculto de sua história.

Conforme foi exposto mais acima, Crítica à razão dualista condensa a ruptura do autor com seu passado desenvolvimentista e a afirmação de seu presente marxista, o que consolidava seu vínculo ao grupo de intelectuais do CEBRAP. Neste contexto, talvez o destaque ao trabalho na SUDENE ao lado de Celso Furtado não contribuísse para o debate que o autor queria promover. Seus colegas do Centro, em especial aqueles que participaram das discussões sobre o texto nos famosos "mesões", sem dúvida sabiam das origens do autor, mas esse era um dado do passado. O que se esperava da obra era uma sintonia com o presente, e Francisco de Oliveira sabia disso. Era preciso evitar que a crítica à teoria do subdesenvolvimento ali realizada assumisse um caráter excessivamente subjetivo. Além disso, não havia $\infty$ a necessidade de explorar essa vinculação, já 亏ें que a questão regional não era o alvo maior de 凶ં sua atenção. Não era conveniente nem neces¿ sário. Após a publicação deste primeiro ensaio que Oliveira sentiu-se à vontade com o presente, identificado a um novo grupo de intelectuais, dentro do qual já conquistara seu lugar. Foi quando o CEBRAP virou o "aqui", o ponto de observação, e a SUDENE o "lá", objeto em relação ao qual já tinha algum distanciamento:

Encontrei no Centro Brasileiro de Análise e Planejamento (CEBRAP), instituição à qual pertenço desde 1970, o clima propício à metamorfose de minha reflexão sobre o Nordeste; aqui, entre os companheiros dessa aventura intelectual, foi possível recuperar a dimensão da criação da SUDENE, a salvo tanto da crônica de um participante quanto de um infantilismo saudosista. Aqui, encontrei o ambiente propício ao trabalho de 'preservar o encanto' da experiência, sem voltar a cair na puerilidade (Oliveira, 2008, p. 132).

A receita de Elegia para uma re(li)gião repete os principais ingredientes de Crítica à razão dualista: estão nela, mas em doses diferentes, o passado desenvolvimentista, o presente marxista e a questão regional. O resultado é diferente não apenas pela mudança na dosagem, mas também pela adição do fator sentimental que o tema, o Nordeste, inevitavelmente trazia ao autor. O primeiro parágrafo do prefácio explicita, de modo corajoso, esse elemento:

Este trabalho foi escrito sob o signo da paixão: paixão de Orieta, do Nordeste, paixão dos operários, trabalhadores e camponeses do Nordeste. Paixão no mais amplo e estrito sentido. Paixão no sentido de Gramsci: o de colocar-se em uma posição e, mediante essa colocação e por causa dela, tentar entender uma tragédia. $\mathrm{O}$ processo social que se procura entender não é um objeto de investigação: é uma causa, uma paixão. Esse posicionamento causará arrepios e um dar de ombros por parte de muitos: é uma obra engajada, que não é, portanto, residência da ciência. Haveria uma multidão de argumentos teóricos para replicar, mas prefiro não seguir esse caminho. Não indaguei, pois, do surgimento da paixão: apaixonei-me apenas; e entrei na corrente, deixei o barco correr (Oliveira, 2008, p. 125, grifo do autor).

A negação do caráter científico da obra, obviamente exagerada, não poderia aparecer em Crítica à razão dualista, que, desde o título, já transmite um ar mais acadêmico, coeren- 
te com a proposta do autor. Ainda que negue, em Elegia, Francisco de Oliveira faz ciência ao esboçar uma história econômica, social e política do Nordeste. Sem ter a pretensão de esgotar o problema, ele partia do pressuposto de que a região ainda carecia de trabalhos com esse alcance, sobretudo, dentro das áreas das ciências sociais e da economia política. O livro Casa Grande \& Senzala, de Gilberto Freyre, é citado como uma "reificação mitológica da 'harmonia' entre senhores e escravos" (Oliveira, 2008, p. 157), no qual faz falta uma compreensão sobre a formação socioeconômica do Nordeste. História Econômica do Brasil, de Caio Prado Jr., e Formação Econômica do Brasil, de Celso Furtado, são livros lembrados como referências incontornáveis para o tema da formação da economia e da sociedade colonial no Brasil, mas nenhum tinha o foco na questão nordestina. Para Oliveira (2008, p. 153-157), os clássicos romances regionalistas eram os que tinham chegado mais longe na tarefa de captar os vários "Nordestes".

Uma boa parte de Elegia é dedicada a contar a história desses "Nordestes", em especial da "região" do açúcar e da "região" do algodão e da pecuária, que se opunham no início do século XX. Esse exercício obedece a uma definição do conceito de "região" apresentada pelo autor ainda na introdução. Para Oliveira (2008, p. 145), entre os vários sentidos que essa noção pode assumir - econômico, social, político, cultural, antropológico, geográfico, histórico -, o ensaio está preocupado com um conceito que "se fundamente na especificidade da reprodução do capital, nas formas que o processo de acumulação assume, na estrutura de classes peculiar a essas formas e, portanto, também nas formas da luta de classes e do conflito social em escala mais geral”. De acordo com essa definição, a "região" seria "o espaço onde se imbricam dialeticamente uma forma especial de reprodução do capital e, por consequência, uma forma especial da luta de classes" (Oliveira, 2008, p. 148). Não há, assim, uma correspondência $a$ priori entre as fronteiras dessas "regiões" e os limites das regiões geográficas tal qual são comumente conhecidas. ${ }^{8}$ Forjados ao longo do processo de "desenvolvimento desigual e combinado" do capitalismo, esses espaços regionais são históricos e, portanto, tendem a desaparecer com a expansão do sistema.

Tomar a história de cada "região" em separado aparece como uma necessidade quando o autor lembra que, no período colonial, o território do Brasil se configurava como um arquipélago, composto por várias ilhas de produção isoladas. Cada uma se desenvolvia a partir das exigências da metrópole portuguesa. Ou das metrópoles, para os casos em que houve ocupação do território por outros impérios, como a França no Maranhão e a Holanda na "região" do açúcar. Logo, entender o Nordeste como uma unidade, sem apreender essas diferenças em sua formação, resultava numa falsificação histórica que atrapalhava a compreensão dos conflitos que se manifestaram em seu interior a partir do final do século XIX. Só após a exposição dessas histórias particulares e dos conflitos, econômicos e políticos, que envolveram o desenvolvimento de cada "região" é que Francisco de Oliveira chega ao momento, já no século XX, em que o avanço da integração nacional escancarou e aprofundou as disparidades regionais, a ponto de exigir a intervenção do Estado de diversas formas, entre as quais se destacava o combate esporádico às secas.

A SUDENE - fundada em 1959, no final do governo de Juscelino Kubitschek - nasceu em meio ao entusiasmo desenvolvimentista e representou um salto na forma como o Estado nacional encarava os problemas do Nordeste. Mas, para Francisco de Oliveira, ela também foi o epílogo de um drama. No período que se estende da segunda metade do século XIX ao início do XX, o Centro-Sul do país vivenciou o

${ }^{8} \mathrm{O}$ conceito econômico e político de "região" permite ao autor pensar, por exemplo, a existência de uma "região" açucareira e de outra "região" algodoeiro-pecuária que coexistiram, durante determinado período, no interior da região Nordeste. Ao longo do ensaio, o uso das aspas serve para diferenciar o conceito construído pelo autor em relação ao senso comum. Essa discussão é apresentada detalhadamente na Introdução, sobretudo em suas partes 2 e 3 (Oliveira, 2008, p. 145-164). 
avanço do cultivo do café, logo seguido pela industrialização, enquanto o Nordeste como um todo assistia ao declínio da produção açucareira e ao avanço da pecuária e das plantações de algodão. Durante esse processo, surgiram conflitos no interior das classes dominantes nordestinas, em especial entre a antiga oligarquia açucareira e a nova fração não açucareira, cuja reprodução - baseada numa acumulação realizada na circulação interna de mercadorias - estreitava seus laços com a nova burguesia industrial do Centro-Sul. Outro efeito foi a tendência a um distanciamento cada vez maior entre a capacidade econômica das principais regiões do país, o que levou o Nordeste a se transformar no coração do que se convencionou chamar de parcela "atrasada" da economia brasileira.

Essa configuração histórica levou à emergência de um padrão "planejado" de "condução e orientação das atividades econômicas", que tinha o Estado como ator fundamental (Oliveira, 2008, p. 138). Para o autor, o surgimento dessa forma não pode ser desvinculado da crise econômica e social que atingia o Nordeste e da esperança sincera da parte de muitos dos envolvidos - entre eles Celso Furtado, que apresentou o projeto da SUDENE a Kubistchek - de que o desenvolvimento vivenciado pelo Centro-Sul do país poderia ser expandido para outras regiões mediante a industrialização, eliminando, nesse processo, os bolsões de "atraso". Em suma, a disparidade econômica inter-regional e a "razão dualista" que imperava no debate sobre o desenvolvimento nacional levaram o governo federal a apostar ڤึ na intervenção planejada sobre a economia da
As contradições da reprodução do capital e das relações de produção em cada uma ou, pelo menos, nas duas principais 'regiões' do país, sinal de uma redefinição da divisão regional do trabalho no conjunto do território nacional, começam a aparecer como conflito entre as duas 'regiões', uma em crescimento, outra em estagnação. É nesse contexto, e tendo por objetivo explícito a atenuação ou pelo menos a contenção da intensificação das disparidades regionais, a correção dos ‘desequilíbrios regionais', que nasce o planejamento regional para o Nordeste.

Esse objetivo geral consta nos documentos originais que antecederam à criação da SUDENE e norteou sua atuação desde os primeiros anos, embora, para Francisco de Oliveira, o efeito prático dessas ideias não se limitasse ao plano traçado. Para ele, além das preocupações econômicas explícitas, a SUDENE possuía uma missão política não menos importante, pois a estagnação - processo histórico detalhadamente descrito pelo autor - abrira espaço para a ascensão das "forças populares" no Nordeste, "constituídas pelos semicamponeses, pequenos sitiantes, meeiros, arrendatários, cuja expressão política mais evidente passou a ser as Ligas Camponesas" (Oliveira, 2008, p. 237). Havia ainda o proletariado urbano, que ganharia peso nos anos 1950 e $60 .{ }^{9}$ Esse duplo avanço dos setores populares, no campo e na cidade, revelava, para Oliveira, a crise de hegemonia das classes dominantes locais, impulsionada tanto por fatores internos, em que pesou o declínio da produção do açúcar, quanto externos, com destaque para a crescente disparidade econômica em relação ao Centro-Sul do país. A situação política e econômica sobre a qual se debruçava a SUDENE aparecia, então, como resultado do "desenvolvimento desigual e combinado" do capitalismo brasileiro. A região Nordeste, como elo mais fraco do sistema, e o Recife, como centro regional, apresentavam, com maior intensidade, as contradições desse processo. Do sucesso do planejamento econômico dependia, portanto, a contenção de uma ameaça à hegemonia burguesa em escala nacional e o avanço do capitalismo monopolista para todo o território. A SUDENE assumiu a forma do "novo Estado no Nordeste": antes atrelado aos interesses da oligarquia açucareira ou algodoeiro-pecuária, ele agora surgia capturado pe-

${ }^{9}$ Desse movimento surgiu a Frente do Recife, fundamental na eleição de Pelópidas da Silveira para a prefeitura da capital, em 1955, com o apoio de socialistas e comunistas. A partir daquela data as forças de esquerda cresceram no interior da Frente e na política regional, a ponto de conduzirem Miguel Arraes à vitória na eleição para o governo de Pernambuco em 1962 (Soares, 1982). 
los interesses da burguesia do Sudeste.

A entrada do capital do Centro-Sul no Nordeste - impulsionada pela SUDENE sob a bandeira da "integração nacional” - foi o que garantiu a execução daquela tarefa, ao promover uma maior homogeneização da economia nacional e ao transformar de maneira irreversível tanto as relações de produção na região Nordeste quanto a divisão regional do trabalho no país. As transformações econômicas não ocorreram "sem o correspondente movimento na estrutura do poder, sem a captura do Estado pela nova coligação de forças que reproduzem o capital de forma agora diferente, a lei do valor não se impõe sozinha" (Oliveira, 2008, p. 202). O papel ativo do Estado nessa intervenção planejada é resumido em outro trecho:

O planejamento emerge aqui como uma 'forma' da intervenção do Estado sobre as contradições entre a reprodução do capital em escala nacional e regional, e que tomam a aparência de conflitos inter-regionais; o planejamento não é, portanto, a presença de um Estado mediador, mas, ao contrário, a presença de um Estado capturado ou não pelas formas mais adiantadas da reprodução do capital para forçar a passagem no rumo de uma homogeneização ou, conforme é comumente descrito pela literatura sobre planejamento regional, no rumo da 'integração nacional' (Oliveira, 2008, p. 149, grifo do autor).

O avanço do capital do Centro-Sul para o Nordeste se deu por meio de uma série de incentivos fiscais que compunham o padrão planejado de intervenção econômica regional da SUDENE, sobretudo após o golpe de 1964. Seu efeito imediato foi a destruição das velhas estruturas de reprodução do capital na região. "Quanto à burguesia industrial nordestina, esta pagou um preço que jamais sonhou; e sua existência é 'irrepetible desde siempre y para siempre', para retomarmos os termos admiráveis de Gabriel García Marquez". Até mesmo a "região" algodoeiro-pecuária, aliada da burguesia industrial do Sudeste, estava condenada: "sobreviveu apenas para poder escrever, se souber - e na maior parte dos casos, não o saberá - o seu próprio epitáfio" (Oliveira, 2008, p. 272-274). Essas "regiões" perderam espaço para a entrada da in- dústria concebida e financiada a partir do Centro-Sul, novo núcleo do sistema. Foi, portanto, uma destruição da qual dependia o processo de expansão-centralização típico do capitalismo monopolista no Brasil, que se tornou, nas palavras de Oliveira (2008), "um país sem fronteiras regionais, a não ser as da memória".

Ao analisar como esse processo se deu, o autor destacou a importância do mecanismo 34/18 como o grande facilitador para a entrada do capital do Centro-Sul no Nordeste. ${ }^{10} \mathrm{O}$ artigo 18 pertence à lei $\mathrm{n}^{0} 3.692$, de 15 de dezembro de 1959, responsável pela criação da Superintendência:

Fica isenta de quaisquer impostos e taxas a importação de equipamentos destinados ao Nordeste, considerados preferencialmente os das indústrias de base e de alimentação, desde que, por proposta da SUDENE ou ouvido o parecer da mesma, sejam declarados prioritários em decreto do Poder Executivo (Brasil, 1959).

O artigo 34 apareceu apenas na lei $\mathrm{n}^{\mathrm{O}}$ 3.995, de 14 de dezembro de 1961, que complementava a anterior. Ele determinava que:

É facultado às pessoas jurídicas e de capital 100\% nacional efetuarem a dedução de até $50 \%$ nas declarações do Imposto de Renda, de importância destinada ao reinvestimento ou aplicação em indústria considerada, pela Sudene, de interesse para o desenvolvimento do Nordeste (Brasil, 1961).

Em 1963, uma modificação dessa lei foi elaborada pelo deputado Gileno de Carli, ligado à burguesia industrial açucareira. Seu principal efeito foi o de retirar a exigência de que as empresas tivessem capital 100\% nacional. A inspiração era a legislação italiana da Cassa del Mezzogiorno, que pretendia incentivar a industrialização do sul daquele país. Essas leis surgiram graças à necessidade de direcionar capital para

${ }^{10}$ Essa discussão reproduz a realizada em outro texto (Oliveira; Reichstul, 1973). Elaborado para o Simpósio de Economia da reunião anual da Sociedade Brasileira para o Progresso da Ciência (SBPC), ele não possui a mesma carga sentimental de Elegia, nem uma visão sociológica e política detalhada do processo que analisa. Sua ênfase é mais econômica, e boa parte do argumento dos autores se constrói a partir do diálogo crítico com um artigo de Albert Hirschman (1967) também dedicado ao mecanismo 34/18. 
o Nordeste e para a SUDENE, até então bastante carente de recursos. O acréscimo de emendas, como o artigo 34, só foi facilitado pelo grande atraso na aprovação do Plano Diretor da Superintendência no Congresso Nacional.

Graças à combinação desses dois artigos, empresas detentoras de grande capital - a maioria do Centro-Sul do país - foram incentivadas a investir no Nordeste em troca de isenções fiscais. Realizava-se, assim, o plano de integrar a economia regional à nacional, porém sem alterar a relação de subordinação já existente: o capital apenas passava pelo Nordeste e, em seguida, voltava para o centro do sistema, dentro ou fora do país. Através das isenções, o Estado descartava uma parcela considerável de tributos a serem captados e os mantinha, como capital, nas mãos dos grandes investidores. A SUDENE chegou a tentar atrair parte desse recurso, ao dar às empresas a opção de destinar o imposto deduzido ao Fundo de Desenvolvimento do Nordeste (Fidene), que seria empregado em projetos industriais aprovados pela Superintendência, mas a alternativa de investimento privado se impunha naturalmente (Oliveira, 2008).

Em suma, para Oliveira (2008, p. 264) a forma de atuação da SUDENE antecipou "a imbricação Estado-burguesia internacional associada", replicada para outras "regiões" e setores de atividade econômica durante a ditadura. Trata-se de uma expansão econômica que se deu por centralização: o Sudeste assumiu o posto de centro do sistema, lugar antes ocupado quase inteiramente pelo mercado internacional, que se relacionava com as economias 员 regionais sem mediação. Esse é o diagnóstico

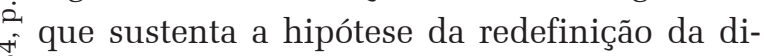
visão inter-regional do trabalho no Brasil, que i guia o estudo. Diante de dados que revelavam que, em 1971, 14 das 24 empresas com projetos próprios no Nordeste tinham origem estrangeira, a conclusão de Oliveira era inevitável:

Os resultados do programa de industrialização, sob a égide do 34/18, são fartamente conhecidos no campo da transferência da hegemonia da burguesia inter- nacional-associada do Centro-Sul para o Nordeste. Os principais grupos econômicos do Centro-Sul transferiram-se para o Nordeste, implantando fábricas e unidades produtivas que, em alguns casos, mesmo quando operem a capacidade ociosa, mesmo quando representem duplicação de produções que, numa visão marginalista, poderiam ser mais econômicas no Centro-Sul, asseguram a homogeneização monopolista do espaço econômico nacional. Ainda quando os resultados do programa de industrialização deixem a desejar em termos de criação de empregos, ou que se afastem do padrão labour intensive que preconizava a Sudene nos seus primórdios, é inegável que a economia do Nordeste integrou-se completamente à economia nacional. Perde, pois, qualquer sentido continuar a falar de 'economias regionais' no Brasil, e o fato de que a própria Sudene continue a tocar uma música antiga vem apenas em desabono do organismo de planejamento regional que, por sinal, deixou de ter qualquer sentido de ‘planejamento' (Oliveira, 2008, p. 264-266).

A apreciação da estrutura da SUDENE e de seus efeitos surge colada, em Elegia, a uma avaliação nada positiva da atuação política da Superintendência no período 1959-1964. Francisco de Oliveira até reconhece a ambiguidade de algumas de suas práticas, em geral decorrentes da tática de não enfrentar os grandes adversários, como os latifundiários, mas essa característica, num cenário em que o conflito era inevitável, levava o órgão a pender para o lado dos interesses da burguesia do Sudeste e, eventualmente, das oligarquias regionais. O órgão também se omitia diante dos programas assistencialistas da Aliança para o Progresso e da USAID, ${ }^{11}$ que pretendiam esvaziar o movimento camponês da região.

O texto de Elegia para uma re(li)gião é bem enfático ao classificar como uma tragédia os efeitos sobre o Nordeste da expansão do capitalismo no Brasil. Essa visão negativa do processo, mais acentuada do que a apresentada em Crítica à razão dualista, justifica-se tanto pelo foco voltado àquela região, vista como o elo mais fraco do sistema, quanto pelo fato de ter sido elaborada depois do fim do "milagre econômico bra-

11 Agência dos Estados Unidos para o Desenvolvimento Internacional. 
sileiro", que revelou melhor as contradições do modelo. Enquanto escrevia o livro, Francisco de Oliveira olhava o período de criação da SUDENE com nostalgia. No final dos anos 1950, o sonho desenvolvimentista estava no auge, e a paixão pelo Nordeste estimulou outros jovens como ele a seguirem Celso Furtado em sua luta pela "modernização" daquela região. Era um tempo de incertezas, no qual o futuro parecia mais aberto, rico em possibilidades. Bastante diferente, portanto, do horizonte sombrio imposto pela ditadura. Esse regime criava, para ele, uma oposição entre Estado e Nação que consistia num enorme impasse, dentro do qual "o peso excessivo dos interesses estrangeiros, a harmonia-competição entre a burguesia internacional-associada e os monopólios do Estado, a luta mortal no processo de concentração e centralização do capital tornaram o país ingovernável, mesmo para os interesses das classes dominantes" (Oliveira, 2008, p. 275). O autor, incomodado com o presente, refugiou-se no passado para, em tom melancólico, pensar o futuro. Ao rever a história do Nordeste e da SUDENE, ele se negava a aceitar que ela acabasse daquela forma, como tragédia, o que o estimulou a escancarar seu desejo de uma ruptura revolucionária e socialista, que aparecia timidamente no final de Crítica à razão dualista. Ela é apresentada como a única solução do impasse nacional, na última frase do livro, depois de já ter sido lembrada, no prefácio, como a única forma de dar sentido à história das lutas do passado:

Esta Elegia não canta o amor do Nordeste passado, que foi o domínio dos latifundiários e dos 'barões' do açúcar, Nordeste este que se projeta agora num folclore que é, sob muitos aspectos, a glorificação de um passado de servidão. Esta Elegia canta o amor do futuro. Não esquece, porém, que, ao cantar, esse futuro se realiza pelo aprofundamento da exploração, neste futuro imediato. [...] Esta Elegia é, pois, o canto de amor da região do futuro e essa região é simultaneamente todo o Brasil e a nova forma de sociedade, isto é, a nação socialista (Oliveira, 2008, p. 130-131, grifo do autor).

A identidade entre a nação e a região, sugerida no final, é irônica. Ela anuncia a realização do sonho do planejamento econômico regional, o projeto da SUDENE, mas invertido: não foi o
Nordeste que se nivelou ao Centro-Sul do Brasil ao alcançar seu patamar de desenvolvimento; foi o Brasil como um todo que se igualou ao Nordeste com o avanço de um modelo econômico baseado na altíssima concentração de renda, na dependência internacional e na reprodução de formas arcaicas de relações sociais e econômicas, como a acumulação primitiva no campo e a informalidade no setor de serviços. Essa conclusão, somada à ideia de que haveria um impasse entre o Estado e a Nação, é reveladora do quanto Francisco de Oliveira permanecia atrelado a algumas categorias de pensamento ligadas ao nacional-desenvolvimentismo.

Diante desse fato, cabe uma questão: como intelectuais e artistas formados no período de 1930-64, em meio ao florescer de grandes discursos e projetos sobre a Nação, poderiam romper completamente com seu passado? Os resíduos deste sempre permaneciam, ainda que como elemento marginal, em suas produções. Em geral colados a um sentimento melancólico, que, em Elegia, são bem sintetizados pelas referências a Cem anos de solidão, de Gabriel García Márquez: "Quando for possível 'decifrar los pergaminos’ da Sudene e de sua experiência - e este trabalho pretende oferecer uma contribuição neste sentido - ficará claro que 'todo lo escrito en ellos era irrepetible desde siempre y para siempre' [...]” (Oliveira, 2008, p. 138).

\section{A atualidade da crítica, quarenta anos depois}

No final dos anos 1970 outro Chico, o Buarque, também colocou, em uma obra, sua visão sobre o processo de modernização conservadora consolidado sob a ditadura. Na letra que escreveu com Roberto Menescal para a música Bye bye Brasil, de 1979, um viajante conta por telefone para a namorada, às pressas, suas aventuras pelos cantos do país. ${ }^{12}$ Seu relato consiste numa sequência de versos sobre as novi-

${ }^{12}$ A letra é de Chico Buarque e a música de Roberto Menescal. A canção foi composta para a trilha sonora de um filme homônimo de Cacá Diegues, no qual artistas viajam o Brasil para fazer espetáculos em raras cidades ainda sem televisão. 
dades que ele encontrou pelo caminho - "já tem fliperama em Macau"; "puseram uma usina no mar" - que acabam contrapostas às imagens do Brasil arcaico, ainda presente, mas já integrado ao moderno - "o chefe dos Parintintins vidrou na minha calça Lee"; "no Tabariz, o som é que nem os Bee Gees”. A combinação do novo e do velho também aparece numa referência ao trabalho precário num centro urbano: "pintou uma chance legal, um lance lá na capital, nem tem que ter ginasial". Outros trechos transmitem o estranhamento do personagem diante do que vê, sobretudo quando constata que o país real não coincide com aquele anunciado pelo discurso oficial: "eu vi um Brasil na tevê”. Um sentimento romântico atravessa toda a letra, em tom de saudade, tanto da namorada, distante, quanto do país do passado: "estou me sentindo tão só”; "eu tenho saudades da nossa canção, saudades de roça e sertão". $\mathrm{O}$ viajante constata que o Brasil tradicional, relatado em outra canção famosa, não é mais o mesmo - "aquela aquarela mudou" - e, consciente da profundidade das transformações, ele se despede do país do passado: "Bye bye Brasil, a última ficha caiu” (Buarque, 1979).

Tanto a letra de Chico Buarque quanto os textos de Francisco de Oliveira sobre o Nordeste apresentam um mesmo tom de adeus, romântico, mas inevitável. Portanto, a comœ paração entre a música e o livro vale a pena. ک 凶ँ que podem ser encontrados em meio à produção de artistas e intelectuais brasileiros no te: a região preservava boa parte das relações políticas, econômicas e sociais arcaicas sem desfrutar de grandes benefícios após sua integração ao polo dinâmico do país. Sua história se assemelhava mais a uma tragédia. Daí a saudade que o autor demonstra do período em que Celso Furtado e a SUDENE prometiam tempos bem melhores. Mas aquele projeto de futuro, não realizado, já era coisa do passado.

A luta pela redemocratização, impulsionada pelo ressurgimento de forças populares em todo o país, alimentou, mais uma vez, a esperança. Engajados naquela disputa e, em especial, na construção do Partido dos Trabalhadores, Francisco de Oliveira e outros intelectuais de sua geração logo sofreriam uma nova decepção, ao notarem que o processo de transição ocorreu, mais uma vez, apoiado num grande esforço para conservar velhas relações sociais e estruturas de dominação. A sobrevivência da Nova República, fruto daquele processo, foi garantida, ao longo da década de 1990, graças a uma agenda que privilegiou a estabilidade econômica e a governabilidade em detrimento da ampliação da democracia, da conquista de novos direitos sociais e do combate às desigualdades. Crítico aos governos de Fernando Henrique Cardoso, seu ex-colega de CEBRAP, Oliveira também se distanciaria do PT logo após a eleição de Lula, quando notou que o novo presidente pretendia manter seu programa refém das exigências do mercado e das regras do jogo parlamentar.

Ao lado de Crítica à razão dualista e de outros textos, de diversos autores, Elegia contribuiu para revelar que o processo de modernização conservadora liderado pelo regime autoritário havia alterado a realidade do país de maneira profunda, de tal forma que, a partir daquele momento, a tarefa de pensar e agir sobre o Brasil envolvia novos e grandes desafios. Eles eram reforçados por mudanças externas, como o avanço da mundialização, a crise internacional da esquerda e as transformações no mundo do trabalho. As qualidades do texto, destacadas neste artigo, são também fundamentais para a compreensão 
de seus defeitos ou, mais precisamente, os limites de seu autor. Francisco de Oliveira teve o mérito de notar e destacar o conjunto de mudanças que colocava em xeque os princípios do nacional-desenvolvimentismo, que guiaram as ações e reflexões de políticos e intelectuais brasileiros na primeira metade do século XX. O diagnóstico era preciso. Porém sua formação, vinculada àquela tradição, impunha incontornáveis limites à sua crítica, mesmo que Oliveira a tenha levado a níveis até então inéditos. Os resíduos nacional-desenvolvimentistas atravessam todo o seu texto, não apenas as passagens mais sentimentais, tomadas por certa nostalgia. Mesmo depois de Elegia, quando as sucessivas mudanças na conjuntura política do país atraíram Oliveira para novos debates e projetos, aquela lembrança um tanto melancólica das promessas frustradas do desenvolvimentismo nunca abandonou por completo sua produção. ${ }^{13}$

Mas as qualidades são, sem dúvida, maiores que os defeitos. Quarenta anos depois de sua primeira publicação, Elegia permanece atual, porque o Brasil de hoje ainda se assemelha, em vários aspectos, àquele que Oliveira descreveu ao longo da década de 1970, repleto de velhas contradições não resolvidas, que assombram o presente e embaralham as perspectivas de futuro. A tragédia que o autor anunciava para o Nordeste se realizou não só para a região, mas para o conjunto do país: uma integração total ao sistema, mas imperfeita, que permite a convivência do mais moderno com o mais atrasado e, pior, depende dela para se reproduzir. Nos textos mais recentes de Oliveira, esse diagnóstico, sintetizado no ensaio O ornitorrinco (2003), alimentou, muitas vezes, uma espécie de paralisia. O autor, após tantas decepções, não enxerga muitas alternativas diante do impasse político, social e econômico do país. Mesmo sem me render à sua perspectiva política, vejo, em seus textos antigos e recentes, bons instrumentos para pensar o Brasil e, apesar das evidentes dificuldades, agir para transformá-lo. Elegia para uma re(li)gião não foge à regra: qua-

${ }^{13}$ Esta é a hipótese central de minha tese de doutorado, dedicada à sua trajetória (Mendes, 2015). renta anos depois, ele ainda fornece um quadro bem fiel do país e de muitos de seus problemas. Graças à qualidade de seu autor, sem dúvida, mas também à teimosa incapacidade de o Brasil acertar contas com o seu passado.

Recebido para publicação em 09 de setembro de 2016 Aceito em 15 de outubro de 2018

\section{REFERÊNCIAS}

BRASIL. Lei n. 3.692, de 15 de dezembro de 1959. Institui a Superintendência do Desenvolvimento do Nordeste e dá outras providências. Diário Oficial [da] República Federativa do Brasil, Brasília, DF, 15 dez. 1959. Disponível em: <http://www.planalto.gov.br/CCivil_03/Leis/19501969/L3692.htm>. Acesso em: 8 nov. 2018.

. Lei n. 3.995, de 14 de dezembro de 1961. Aprova o Plano Diretor da SUDENE, para o ano de 1961, e dá outras providências. Diário Oficial [da] República Federativa do Brasil, Brasília, DF, 14 dez. 1961. Disponível em: <http:// www2.camara.leg.br/legin/fed/lei/1960-1969/lei-3995-14dezembro-1961-376756-publicacaooriginal-1-pl.html > . Acesso em: 8 nov. 2018.

BUARQUE, C. "Bye, bye Brasil”. Melodia: Roberto Menescal, 1979. Disponível em: < http://www. chicobuarque.com.br/letras/byebyebr_79.htm>. Acesso em: 8 nov. 2018.

HIRSCHMAN, A. "Desenvolvimento industrial no Nordeste brasileiro e o mecanismo de crédito fiscal do artigo 34/18”. RBE, ano 21, n. 4, dez. 1967.

MANTEGA, G.; REGO, J. M. (Org.). Conversas com economistas brasileiros II. São Paulo: Editora 34, 1999.

MENDES, F. O ovo do ornitorrinco: a trajetória de Francisco de Oliveira. 2015. 316 f. Tese (Doutorado em Sociologia) Instituto de Filosofia e Ciências Humanas, Universidade Estadual de Campinas, Campinas, 2015.

MONTERO, P.; MOURA, F. (Org.). Retrato de grupo: 40 anos do Cebrap. São Paulo: Cosac Naify, 2009.

OLIVEIRA, F. de. Crítica à razão dualista / O ornitorrinco. São Paulo: Boitempo, 2003.

. A noiva da revolução / Elegia para uma re(li)gião. São Paulo: Boitempo, 2008.

; REICHSTUL, H. P. "Mudanças na divisão interregional do trabalho no Brasil". Estudos CEBRAP, v. 4, p. 131-168, 1973.

RIDENTI, M.; MENDES, F. "Do dualismo ao ornitorrinco: entrevista com Francisco de Oliveira". Caderno CRH, Salvador, v. 25, n. 66, p. 601-622. set./dez. 2012.

RODRIGUES, L. S. A produção social do marxismo universitário em São Paulo: mestres, discípulos e "um seminário" (1958-1978). 2011. 565 f. Tese (Doutorado em História Social) - Faculdade de Filosofia, Letras e Ciências Humanas, Universidade de São Paulo, São Paulo, 2011.

ROMÃO, W. de M. Sociologia e política acadêmica nos anos 1960: a experiência do CESIT. São Paulo: Associação editorial humanitas, 2006.

SOARES, J. A. A Frente do Recife e o Governo Arraes. Rio de Janeiro: Paz e Terra, 1982.

SORJ, B. A construção intelectual do Brasil contemporâneo: da resistência à ditadura ao governo FHC. Rio de Janeiro: Jorge Zahar, 2001. 


\section{FORTY YEARS OF AN ELEGIA: Francisco de Oliveira and the Northeast}

\section{Flávio Mendes}

The classic essay of Francisco de Oliveira, Elegia para uma re(li)gião were completed forty years in 2017. Dedicated to analyse the trajectory of SUDENE Superintendência de Desenvolvimento do Nordeste, where the sociologist worked between 1959 and 1964, the paper became a reference for the debates on the regional problems in Brazil. Oliveira criticizes the model of development that guided SUDENE's activities, especially during the dictatorship. He shows the impact of "milagre econômico" on Northeast and the changes in regional division of labour in the country. The essay expresses also the opinions of some left wing intellectuals about the social and economic situations. From the analysis of Oliveira's main arguments and the debate on the atmosphere surrounding the essay's creation, this article aims to remind the essay's impact on Brazilian social sciences in the 1970s and, finally, briefly reflect on its importance for the present.

\section{QUARANTE ANS D'ÉLEGIE: Francisco de Oliveira et le nord-est}

Flávio Mendes

Keywords: SUDENE. Oliveira, Francisco de. Mots-clés: SUDENE. Oliveira, Francisco de. Nord-

Northeast - Brazil. Developmentalism. Dictatorship. est - Brésil. Développementisme. Dictature.

La publication du livre Elegia para uma re(li)gião, de Francisco de Oliveira, va faire quarante ans en 2017. Dedié a analiser la trajectoire de la SUDENE, où le sociologue a travaillé entre 1959 et 1964, le texte est devenu une référence pour le debat sur la question regionale au Brésil. Au-delà de la critique au modèle de développement qui a guidé les actions de la SUDENE, surtout pendant la dictature, Elegia montre l'impact du "milagre econômico" sur le Nordest brésilien et les changements dans la division régionale du travail du pays. Le texte exprime, aussi, la vision d'une partie des intellectuels de gauche sur la situation social et économique. D'après l'anayse des principaux arguments utilisés par l'auteur et du débat sur le climat qui a encouragé la création du livre, cet article vise à rappeler sont impact sur les sciences sociales au Brésil pendant les annés 1970 et, enfin, réfléchir brièvement sur sa pertinence.

Flávio Mendes - Doutor em Sociologia pela UNICAMP. Trabalha com temas relacionados ao Pensamento Social no Brasil e na América Latina. Autor, entre outros textos, do livro Hugo Chávez em seu labirinto: o Movimento Bolivariano e a política na Venezuela, pela editora Alameda (São Paulo, 2012). 